\title{
Industrial air emissions in Portugal: 2008 report
}

\author{
A. Martins \\ Science and Technology College, New University of Lisbon, Portugal
}

\begin{abstract}
Monitoring air pollutant emissions of large stationary sources is necessary to ensure compliance with environmental legislation. Pollutant emissions to the atmosphere from the major air polluting industries in Portugal are subjected to specific limits, according to the specific industrial sector and specific emitting source, on the basis of a self-control system. The results of the respective measurements are reported to the competent authority - Portuguese Environment Agency (APA).

This study was carried out with the results of the main Portuguese industries (57), calculated for different source emission and industrial sectors, according to the respective emission limit values (ELV), which were 96,5\% fulfilled in 2008 (96,9\% in 2007), for the continuous emissions results.

The annual report serves as a measure of Portuguese progress in reducing air pollution emissions as a result of mandatory and voluntary controls and of continuous changes in national activity. The emission level concerning the ELV and total legal non-compliances is also presented, from comparison to the 2007 results, according to the emission source and its activity sector.

Thus, an overview of the Portuguese legal framework is shown, and referenced new environmental licenses in order to reduce air pollution. These include promotion of the best available technologies and strengthening and effectively implementing emission standards, which can be seen, by analysis of specific statistical information, about frequency distribution on emission level.

This study had the particular challenge of developing an overview of available methodologies in order to support decision-making concerning air pollution, in particular, to this specific research.
\end{abstract}

Keywords: air pollution, industrial, stationary source emissions, DSS. 


\section{Introduction}

\subsection{The relevance of air pollution emissions and their management}

Air pollution is "at least as old as the first fire" (Goklany [1]). It is a serious problem in many heavily populated and industrialized areas, especially in areas where pollution sources and human population are concentrated. To prevent or minimize the damage caused by atmospheric pollution, suitable monitoring systems are needed that can rapidly and reliably detect and quantify pollution sources for monitoring by regulating authorities.

A condition of "air pollution" may be defined as a situation in which substances that result from anthropogenic activities are present at concentrations sufficiently high above their normal ambient levels to produce a measurable (undesirable) effect on humans, animals, vegetation or materials. It is now clear that dense urban centres and industrialized regions are just "hotspots" in a continuum of trace species concentrations over the entire Earth (Seinfeld and Pandis [2]).

Since the industrial revolution, the quality of the air we breathe has deteriorated considerably - mainly as a result of human activities. Rising industrial and energy production, the burning of fossil fuels and the dramatic rise in traffic on our roads all contribute to air pollution in our towns and cities which, in turn, can lead to serious health problems, European Commission [3].

Air pollution is defined as "a state of the atmosphere in which substances that harm human or plant health or corrode materials exist in concentrations above their normal or background levels" (Bates and Caton [4]). The complexity of air pollution comes from not only the multiple sources or multiple pollutants, but also from the complex dispersion and transformation of the pollutants in the air that is influenced by meteorological and topographical factors such as temperature, humidity, wind direction and speed (Clench-Aas et al. [5]). Thus, the sources of pollution may be in one country but the impact of pollution may be felt elsewhere, such is the impact of air pollution.

The atmosphere can be likened to an enormous chemical reactor in which a myriad of species are continually being introduced and removed over a vast array of spatial and temporal scales, in which numerous physical and chemical processes occur simultaneously (Seinfeld and Pandis [2]).

To develop efficient strategies for pollution control, it is essential to assess both the costs of control and the benefits that may result from them. These benefits will often include improvements in public health, including reductions in both morbidity and premature mortality. The magnitude of the benefits of pollution control depends on the level of air pollution, the expected effects on health of the pollutants (dose-response), the size of the population affected and the economic value of these effects (Ostro et al. [6]).

The effect of pollution is rarely very large (Clench-Aas et al. [5]) many of the impacts of air pollution on the environment and on human health are complex and - at the local or individual level - often small: what make them important is the large areas and populations at risk. In order to understand and assess these 
risks it is vital to be able to monitor conditions over the country and to compile and analyze data from different areas in a consistent form.

Despite significant improvements in Europe's air quality driven by legislation and other factors, air pollution continues to have serious human health and environmental effects. To combat air pollution, the EU has introduced a range of policy measures, and has signed up to a number of international conventions and agreements. Proper implementation and monitoring of these policies requires reliable, consistent and detailed information on air quality.

\subsection{Industrial air pollution decision making}

Industrial air quality management faces new and continuing challenges, driven by new legislation and public awareness, the challenge is to integrate scientific tools of analysis with the environmental planning and management process, to involve a large and diverse audience and participants in the policy and decision making processes, and to support new functions such as the information of the public.

Decision making processes involve intelligence (defining the need for decision making or problem-solving), design (preparing alternative courses of action) and choice (evaluating alternatives and selecting the most appropriate strategy) (Boots [7]).

At the local scale, exposure assessment may be seen as part of a decisionsupport tool for local authorities for improving air quality management. An industrial air quality management system should encompass: air quality monitoring, emission inventories, air quality and exposure mapping, air quality and exposure impact assessment of various traffic control strategies in support of evaluation of action plans, information to the public about past and present air quality levels but also forecasts for next day levels (Jensen [8]).

The development and application of a decision support system (DSS) for industrial air emissions management must involve the emissions data availability, from continuous monitoring at a stack level and the knowledge of compliance degree of related to the legal framework, and its evolution. Better and shared information is one of the elements of an improved decision making process, so, it's important to promote the requirements for free public access to environmental information, both as a passive right-to-know and as an active mandate to inform the affected public by governmental institutions or companies.

\section{Approach and methods}

The particular challenge addressed to this paper is the development of a consistent approach for quantification of atmospheric emissions from stationary sources in order to analyse the compliance to the legal requirements and support decision-making, by the responsible entities.

The current research work is mainly focused on the emissions from the stationary source domain, specifically for large emission sources (LES), 
monitoring continuously the pollutants, and has the objective to overview the Portuguese legislation on industrial emissions, as basis for the analysis of air emissions compliance, by looking towards those results.

The scope of this study is to address the analysis of the current situation and trends in Portugal with respect to the industrial air emissions and the assessment of the legal compliance regarding emission limit values, the relevance of the pollutants emitted by industrial sources and their evolution between 2007 and 2008.

In order to achieve the defined objectives, it was collected and processed all the statistical data received in APA (acronym of Agência Portuguesa do Ambiente as Portuguese Environment Agency), aiming to characterise industrial emissions levels, namely the measured concentrations of pollutant and emission limit values. The pollutant emissions from LES, are subjected to specific limits, according to the specific industrial sector and specific emitting source, and are measured on the basis of a self-control system, which means that the responsibility of monitoring and reporting the measurements to the Portuguese competent authority (APA) lies on the operator side (Gomes [9]).

It is intended in this research, to show the conclusions about the legal compliance of emissions data collected from the universe of industrial sources by activity sector (See Table 2), that meets the industrial air pollutants legal framework (See chapter 3).

It is also presented some information based on the emission level to each pollutant to the set of emission sources, according to the respective ELV. The Figure 1 shows some graphs with the mean relation between the annual mean concentration for the set of emission sources, and each corresponding ELV: Emission Level = annual mean concentration / ELV (percentage).

\section{Portuguese legal framework - industrial air emissions monitoring results}

Air pollution is regulated in Portugal, primarily, by a law setting up the basic principles of all Portuguese regulations on the environment, which was approved by the parliament in 1987 (Law 11/87), fulfilling the commitment of the Portuguese government towards the protection of the environment as defined in the Portuguese State Constitution [9].

Based on this essential law, other sectored laws were published, namely the Air Act, the Decree Law 352/90 of November $9^{\text {th }}$ on Air Quality Protection and Atmospheric Emissions, integrates both air quality and industrial emissions regulations, its regulating Ordinance 286/93 of March $12^{\text {th }}$ on Air Pollution Concentration Limits.

Currently, the air emissions control in Portugal is done by application of the Decree-Law 78/04, of April $3^{\text {rd }}$ that revised the Decree-Law 352/90, and cover emissions such as point sources released by industrial, commercial and institutional establishments or other services, depending on installed process capacity or combustion power. 
This legal instrument still send to its regulation diplomas, Ordinance 286/93, March $12^{\text {th }}$, and Ordinance $80 / 2006$, of January $23^{\text {rd }}$, that establishes two mass flow thresholds, a minimum and a maximum to each pollutant, to distinguish point emission sources from three groups: low, medium and large capacity.

As each source type has different monitoring requirements, this approach contributes to a more cost-effective emission control by the operator and by the administration:

- LES, emitting above maximum mass flow threshold for a specific pollutant, should carry out continuous monitoring of that pollutant;

- medium emission sources, which emission rates range between minimum and maximum threshold, need to perform stack gas monitoring twice a year;

low emission sources, with emissions for a specific pollutant below minimum threshold, must only perform one stack characterization every three years.

The Decree Law 242/2001 of August $31^{\text {st }}$ regulated the reduction of the direct and indirect effects of $\mathrm{COV}$ emissions resulting from the application of organic solvents in certain activities and facilities, thereby implementing Council Directive 1999/13/CE of March $11^{\text {th }}$.

In general terms, the authority responsible for enforcement of such legislation is the Portuguese Environmental Agency (APA).

The legal framework on industrial emissions comprises other two major regulations, which were transposed to the Portuguese Law through the respective Decrees-Law, namely:

- Large Combustion Plants (Decree-Law 178/2003, of August $23^{\text {rd }}$ ), on the limitation of certain pollutants into the air from large combustion plants;

- the Waste Incineration Directive (Decree-Law 85/2005, of April 28 $8^{\text {th }}$ ), on the incineration of waste.

Related to the monitoring, and in particular driven by any legal noncompliance and thus unlawfulness with regulations in force is the formulation of general policies and strategies to reduce emissions and thus ambient concentrations, to comply with emission limit values (ELV).

About $85 \%$ of considered plants (in this study) are integrated pollution prevention and control (IPPC) installations, subjected to the application of best available techniques (BAT) which are the most effective techniques to achieve a high level of environmental protection, taking into account the costs and benefits.

The terms of Portuguese legal compliance to atmospheric industrial emissions, include the obligation, by each operator, to sent results to the national authority responsible (APA), of:

- continuous monitoring self-control results, in accordance with DecreeLaw 78/2004 of April $3^{\text {rd }}$, and Order No. 79/95, 12-01-1996, quarterly;

- periodic measurements, in general, twice in each calendar year, sent until sixty days after the measure. Waste incineration and coincineration plants may have a different monitoring frequency, namely for heavy metals, dioxins and furans according to the Decree-Law 
No. 85/2005 and Exploration Licenses requirements, which can vary between the quarterly and annual.

\section{Results and discussion}

Results were collected from 57 main plants. From those, 143 emissions sources provide information about continuous monitoring and 256 also sent periodic measurements results to APA, in 2008, in both cases, more than in 2007.

Table 1: Comparison between the number of continuous monitoring facilities (SO2, NOx, Part, CO, TOC, Cl, F, H2S and NH3), and emissions sources with continuous monitoring (C) and periodic measurements (P), in 2007 and 2008.

\begin{tabular}{|c|c|c|c|c|c|c|c|c|c|c|c|}
\hline & C & P & SO2 & NOx & Part & CO & TOC & Cl & F & H2S & NH3 \\
\hline 2008 & 143 & 256 & 81 & 81 & 103 & 38 & 18 & 18 & 18 & 12 & 5 \\
\hline 2007 & 119 & 200 & 70 & 75 & 94 & 37 & 18 & 18 & 18 & 12 & 0 \\
\hline
\end{tabular}

Table 2 presents the percentage of legal fulfilment of the continuous monitoring results taking into account the applicable ELV, according to each represented activity sector and measured pollutant. For the periodic

Table 2: Fulfillment pollutant percentage (continuous measurements), by activity sector. Number of ELV non-compliances to periodic measurements.

\begin{tabular}{|l|c|c|c|c|c|c|c|c|c|c|c|}
\hline & \multicolumn{9}{|c|}{ Continuous monitoring } & \multicolumn{3}{|c|}{ Periodic } \\
\hline $\begin{array}{l}\text { Activity Sector } \\
\text { (number of plants) }\end{array}$ & SO2 & NOx & Part & CO & TOC & Cl & F & H2S & NH3 & Total & Total \\
\hline Agro-Industrial (1) & $100 \%$ & $22 \%$ & $33 \%$ & $50 \%$ & & & & & & $52 \%$ & 3 \\
\hline Cal (2) & $75 \%$ & & & & & & & & & $75 \%$ & 5 \\
\hline Cement (8) & $100 \%$ & $98 \%$ & $100 \%$ & $100 \%$ & $100 \%$ & $100 \%$ & $100 \%$ & & & $100 \%$ & 1 \\
\hline Ceramic (11) & $100 \%$ & & & & & & & & & $100 \%$ & 4 \\
\hline Chemical (3) & $100 \%$ & $100 \%$ & $100 \%$ & & & & & & & $100 \%$ & 13 \\
\hline Cogeneration (6) & $100 \%$ & $94 \%$ & $100 \%$ & $97 \%$ & & & & & & $96 \%$ & 13 \\
\hline Expanded clays (1) & $100 \%$ & & & & & & & & & $100 \%$ & 0 \\
\hline Glass (2) & $100 \%$ & $100 \%$ & $100 \%$ & & & & & & & $100 \%$ & 7 \\
\hline $\begin{array}{l}\text { Hazardous waste } \\
\text { incineration (2) }\end{array}$ & $100 \%$ & $100 \%$ & $100 \%$ & $100 \%$ & $100 \%$ & $87 \%$ & $89 \%$ & & & $95 \%$ & 1 \\
\hline $\begin{array}{l}\text { Non-hazardous waste } \\
\text { incineration(1) }\end{array}$ & $100 \%$ & $100 \%$ & $100 \%$ & $100 \%$ & $100 \%$ & $100 \%$ & $100 \%$ & & & $100 \%$ & 0 \\
\hline Power Stations (7) & $100 \%$ & $100 \%$ & $100 \%$ & $100 \%$ & & & & & & $100 \%$ & 1 \\
\hline Pulp (6) & $95 \%$ & $98 \%$ & $82 \%$ & $82 \%$ & & & & $92 \%$ & & $90 \%$ & 1 \\
\hline Refinery (2) & $99 \%$ & $100 \%$ & $89 \%$ & & & & & & & $96 \%$ & 3 \\
\hline Synthetic fibers (1) & & & $100 \%$ & & & & & & & $100 \%$ & 0 \\
\hline $\begin{array}{l}\text { Urban waste } \\
\text { incineration (2) }\end{array}$ & $100 \%$ & $97 \%$ & $95 \%$ & $100 \%$ & $100 \%$ & $93 \%$ & $100 \%$ & & $100 \%$ & $98 \%$ & 0 \\
\hline Wood fibers (1) & & & $100 \%$ & & & & & & & $100 \%$ & 2 \\
\hline Wood panels (1) & & $100 \%$ & $92 \%$ & $50 \%$ & $0 \%$ & & & & & $60 \%$ & 0 \\
\hline Total & $99 \%$ & $95 \%$ & $95 \%$ & $95 \%$ & $97 \%$ & $98 \%$ & $92 \%$ & $100 \%$ & $96,5 \%$ & 54 \\
\hline
\end{tabular}


measurements, it is presented, in the last column, the number of ELVs noncompliances, to the set of pollutants.

It's important to note that the calculation reflects the number of months with ELV non-compliance, in percentage of the total of months with measurements. The value of $100 \%$ corresponds to a total compliance with the ELV. A bellow percentage and the lower ones correspond to a growing unlawfulness (months with non-compliances, related to the set of months with continuous emissions data).

Considering the continuous emissions monitoring results, sent to APA, about 2007 and 2008, it's possible to trend a line to some parameters and proceed to the analysis of changes in terms of non-compliances, as well the increases and decreases of annual mean concentrations verified to a set of emissions sources (the average annual is normally the average of 12 monthly mean values obtained along the calendar year), which results are presented in Table 3.

Table 3: Non-compliances evolution (continuous monitoring), between 2007 and 2008. Number of increases and decreases in annual mean concentrations to the set of the emission sources that monitor their pollutant continuous.

\begin{tabular}{|l|c|c|c|c|c|c|c|c|}
\hline & SO2 & NOx & Part & CO & TOC & CI & F & H2S \\
\hline Non-compliance evolution & $\mathbf{+ 1 0}$ & $\mathbf{- 2 2}$ & $+\mathbf{1}$ & $\mathbf{+ 6}$ & $\mathbf{+ 9}$ & $\mathbf{+ 7}$ & $\mathbf{+ 5}$ & $+\mathbf{6}$ \\
\hline Anual mean concentration increases & 24 & 26 & 35 & 17 & 8 & 8 & 4 & 8 \\
\hline Anual mean concentration decreases & 35 & 46 & 48 & 21 & 6 & 7 & 9 & 0 \\
\hline
\end{tabular}

It should be noted that an increase of pollutant air emission concentrations may not represent an increase in pollution load (mass), because it depends on the volumetric flow released to the atmosphere and operation time.

Beside, the environmental licenses and legislation updating may require amendments (typically, reductions) of the ELV, reason why, it's presented, in Table 4, information about the evolution of the ELV to the set of emission sources, measured continuously, between 2007 and 2008.

Table 4: ELV evolution, between 2007 and 2008, to each continuously measured pollutant. Number of ELV that changed (increase or decrease).

\begin{tabular}{|l|c|c|c|c|c|c|c|c|}
\hline & SO2 & NOx & Part & CO & TOC & Cl & F & H2S \\
\hline ELV Evolution & $-10 \%$ & $-13 \%$ & $-13 \%$ & $-4 \%$ & $0 \%$ & $-5 \%$ & $0 \%$ & $0 \%$ \\
\hline Number of ELV increases & 0 & 0 & 0 & 0 & 0 & 0 & 0 & 0 \\
\hline Number of ELV decreases & 18 & 19 & 23 & 2 & 0 & 1 & 0 & 0 \\
\hline
\end{tabular}

Figure 1 presents graphical representation of a frequency distribution, each one concerning to the continuous measured pollutant, presented as the relative frequency (\%), per emission level classes and distributed as the following, inclusive upper limit: less than $20 \%$ of ELV; $20 \%$ to $40 \%$ of ELV; $40 \%$ to $60 \%$ of ELV; $60 \%$ to $80 \%$ of ELV; $80 \%$ to $100 \%$ of ELV; above the ELV. 

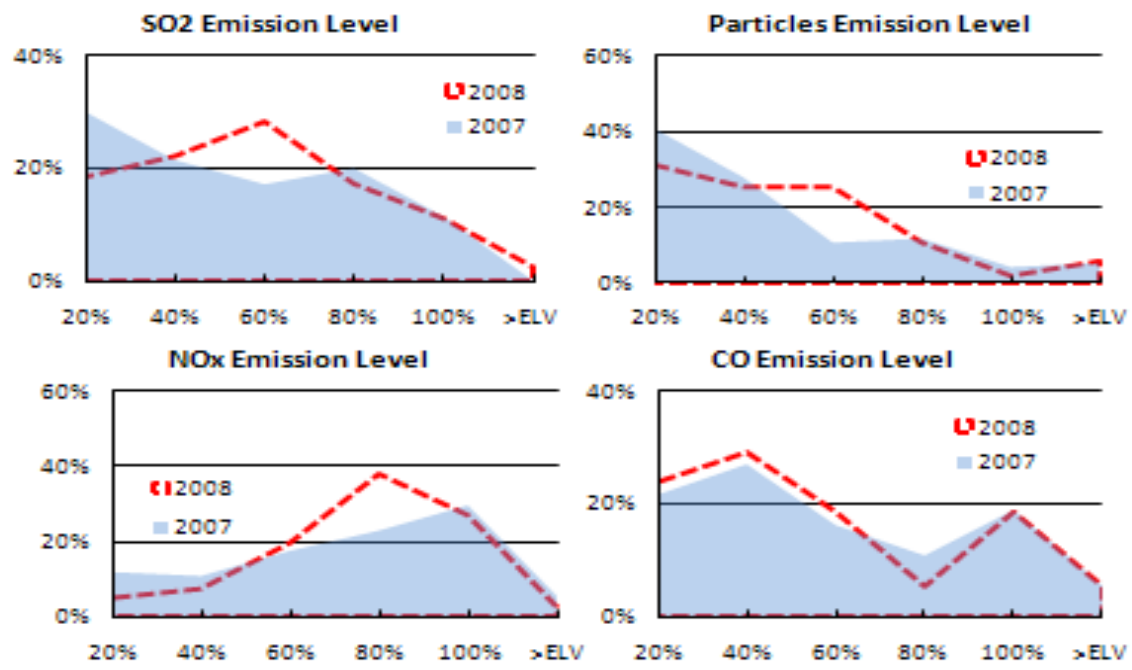

F Emission Level
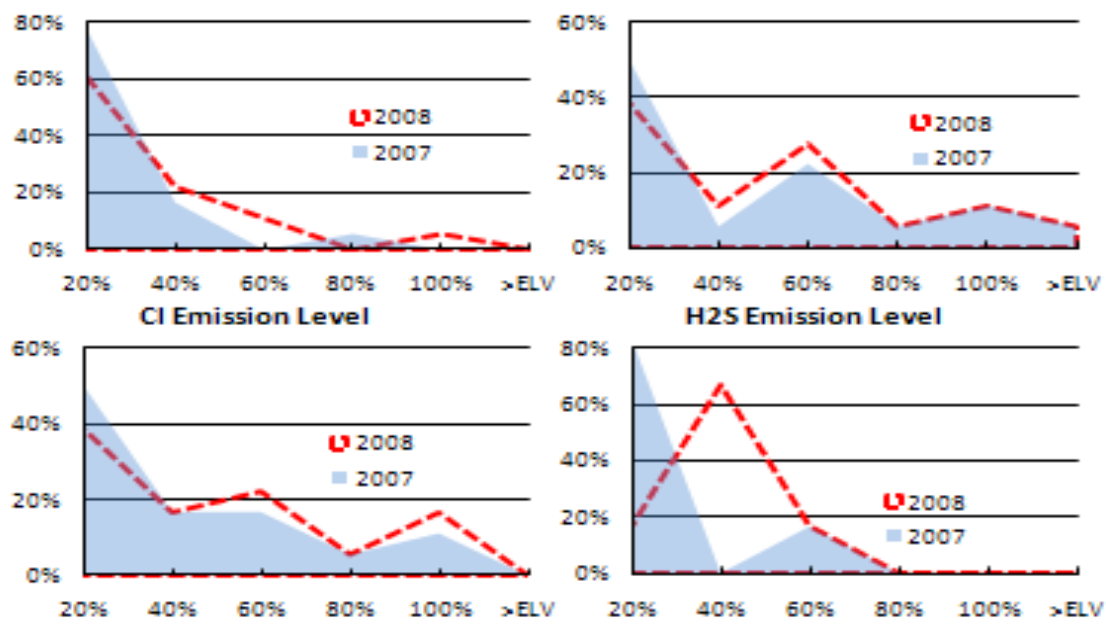

Figure 1: Graphical representation of a frequency distribution of emission level to each pollutant continuously measured, to the set of emission sources.

First of all, the frequency distribution of emission level, allow the analyses of which pollutants have a very comfortable ELV, and in another hand, which pollutants requires a more effective emissions management by the side of operator.

\section{Conclusion}

This research provides the national annual report, in order to verify the compliance to the legal regulatory requirements, from the Portuguese main 
emissions sources, which have continuous monitoring of pollutants. It's possible to verify that the worst pollutants are $\mathrm{H} 2 \mathrm{~S}$ (92\% of fulfilment, although actually only have been measured in pulp plants), particles, CO and TOC (95\%), and best one was NH3 (full compliance).

The worst activity sectors (lower percentage of compliance), were the agroindustrial (52\%) and manufacture of wood panels $(60 \%)$, both represented with only a single plant.

There were 54 non-compliances identified to periodic measurements, to the set of pollutants, in this particular, the worst activities sectors were the chemical and cogeneration ones.

None NH3 result exceeded its ELV, as well the plants from expanded clays, non-hazardous waste incineration and synthetic fibers, which didn't have any legal non-compliance.

The overall 2008 legal compliance to the pollutants continuous emissions results, was $96.5 \%$ (96,9\% in 2007), so occurring $3.5 \%$ of analyzed months results exceeding at least one legal compliance condition.

Comparing 2008 and 2007 data, there were more continuous monitoring noncompliances for the pollutants SO2 $(+10)$, particles $(+1), \mathrm{CO}(+6)$, TOC $(+9), \mathrm{Cl}$ $(+7), \mathrm{F}(+5)$ and $\mathrm{H} 2 \mathrm{~S}(+6)$ and less for NOx $(-22)$. However, for most of measured pollutants ( $\mathrm{SO} 2, \mathrm{NOx}, \mathrm{CO}$ and $\mathrm{F})$, there were more emissions sources that decreased its annual average concentrations, which can be related to the adoption of best available techniques and improved treatment systems, or the internalization of best practices and suitable emissions management.

Graphical representation of a frequency distribution of SO2, NOx and particles emission level, shows increasing 2008 mean concentrations related to corresponding ELV, however, they were the same pollutants that more largely decreases the ELV (SO2 (10\%), NOx (13\%) and particles $(13 \%))$, so both facts may be related.

The frequency distribution of SO2, NOx and particles emission level, allows the conclusion that, in 2008, the mean ELV, was less comfortable to be fulfilled, than in 2007, as well to the $\mathrm{Cl}, \mathrm{F}$ and $\mathrm{H} 2 \mathrm{~S}$ results. CO and TOC show similar behaviour.

The two years data comparison (2007 and 2008), show the ELV suitability trend and give more information to an effective decision making process. The ultimate objective, however, must be to improve environmental planning, policy making and management, and eventually, the environment.

\section{References}

[1] Goklany, I. M., Clearing the Air, CATO Institute, 1999.

[2] Seinfeld, John H., Pandis, S. N., Atmospheric Chemistry and Physics: From Air Pollution to Climate Change, A Wiley-InterScience Publication, John Wiley \& Sons, Inc., ISBN 0-471-17815-2, 1998.

[3] URL 1: Proposal for a Directive of the European Parliament and of the Council on industrial emissions (integrated pollution prevention and control). 
[4] Bates, D. V. \& Caton, R.B., A Citizen's Guide to Air Pollution, 2nd Ed. David Suzuki, Foundation, Vancouver, 2002.

[5] Clench-Aas J., Bartonova A., Bohler T., Gronskel K. E., Slvertsen B., Larssen S. Air pollution exposure monitoring and estimating, Part I. Integrated air quality monitoring system, In J. Environ. Monit., 1, 313-319, 1999.

[6] Ostro B., Estimating the health effects of air pollutants: a method with an application to Jakarta, Policy Research Working Paper Series 1301, The World Bank, 1994.

[7] Boots, B., Developing local measures of spatial association for categorical data, Journal of Geographical Systems, 5(2), 139-160, 2003.

[8] Jensen S. S., Mapping human exposure to traffic air pollution using GIS, Journal of Hazardous Materials 61, 385-392, 1998.

[9] Gomes J. F. P., Profile: Air Quality Regulation Policy in Portugal, European Environment Eur. Env. 14, pp. 40-49, 2004. 